\title{
A developmental analysis of the learning and short-term-memory processes mediating performance in conditional-spatial discrimination problems
}

\author{
CARL ANDREW CASTRO, RICHARD PAYLOR, and JERRY W. RUDY \\ University of Colorado, Boulder, Colorado
}

\begin{abstract}
The development of the rat's ability to use its memory for recent events to control its choice behavior was examined in a conditional-spatial discrimination task. Rats 21 , 28, or 38 days old were trained to escape to a platform located at the end of one arm of a water-filled T-maze. Location of the platform on a choice run was conditionally related to the outcome of the previous forced run. In Experiment 1 the pups were required to solve a win/shift version of the problem: the escape platform on the choice run was located in the arm that was blocked on the forced run. Pups at all ages solved the problem; however, performance during acquisition was age-related. The youngest pups required almost twice as many trials to reach criterion as did the oldest pups. The pups' short-term memory was further challenged by tests with $30-, 60$-, or 180 -sec intervals separating the forced and choice runs. The oldest pups were able to perform well above chance at all delay intervals, but the choice performance of pups 25 and 31 days old on the test day fell to chance when they were tested at the 60 - and $180-\mathrm{sec}$ intervals, respectively. The results of two other experiments suggest that the impaired acquisition performance displayed by the younger animals was not the result of age-related differences in response predisposition the animals bring to the task or to their being unable to remember the outcome of the forced run. Some implications of these findings for brain maturation are discussed.
\end{abstract}

The rat is quite immature at birth, but by the time it is about 21 days old many of the processes that enable it to learn and remember are functional. Rat pups easily condition to olfactory, taste, auditory, and visual stimuli (Coulter, Collier, \& Campbell, 1976; Hyson \& Rudy, 1984; Johanson \& Hall, 1982; Johanson \& Teicher, 1980; Moye \& Rudy, 1985; Rudy \& Cheatle, 1977, 1979; Rudy \& Hyson, 1984; Spear, 1979; Spear \& Kucharski, 1985; Vogt \& Rudy, 1984). Pups also solve both successive and simultaneous brightness discriminations (Rudy \& Castro, 1987) and are adept at spatial navigation learning (Rudy \& Paylor, 1987; Rudy \& Stadler-Morris, 1987; Rudy, Stadler-Morris, \& Albert, 1987; Sutherland \& Dyck, 1984).

Nevertheless, other evidence suggests that the processes that mediate memory for recently experienced events may continue to mature well into the 4th postnatal week. For example, Moye and Rudy (1987a) found that rats only 17 days old strongly conditioned to a visual conditioned stimulus (CS) that terminated with the unconditioned stimulus (US). Pups this age failed to condition, however,

This research was funded in part by National Science Foundation Grant BNS-8207654 awarded to Jerry W. Rudy. Richard Paylor was supported by NICHD Training Grant HDO7288. We thank Robert Sutherland for his valuable comments on earlier drafts of this article. Requests for reprints should be sent to Jerry W. Rudy, Department of Psychology, University of Colorado, Boulder, CO 80309. if CS termination was separated from US occurrence by either 10 or $30 \mathrm{sec}$. By 28 days of age, they strongly conditioned even when the CS was terminated $30 \mathrm{sec}$ prior to US onset. It is important to note that if the CS and US are temporally separated, conditioning depends upon a memory representation (activated by the CS) enduring over the delay interval. Moye and Rudy's data thus suggest that the processes that enable the memory for the recently experienced CS to endure over the delay interval continue to mature well after the basic associative processes are functional.

In the present series of experiments, we further investigated the development of the rat's memory for recent events by examining its performance in a more complex situation, a conditional-spatial discrimination task. Rats of different ages were trained to escape to a platform located at the end of one arm of a water-filled T-maze. Each trial consisted of two runs, a forced run and a choice run. On the forced run, one arm of the maze was blocked and the animal had to escape to the platform in the unblocked arm. On the choice run, neither arm was blocked and the platform was placed in either arm of the maze. There were no physical differences in the maze that allowed the animal to discriminate which arm contained the platform. Platform location on the choice run, however, was conditionally related to the location of the platform on the preceding forced run. On the choice trials of the win/shift version of this problem, the escape platform was placed in the 
arm that was blocked on the forced run. On the choice trials of the win/stay problem, the escape platform was located in the arm that contained the platform on the forced run.

In principle, the conditional relationship between forced runs and choice runs provides the subject with a basis for dividing the choice runs into two independent problems and thereby making the correct choice on each trial. To take advantage of the conditional relationship, however, the subject must be able (1) to remember the outcome of the forced run, and (2) to integrate this memorial information with the events experienced on the choice trial.

\section{EXPERIMENT 1}

The present experiment was designed to examine the development of these theoretically independent memory capacities, the ability to remember recently experienced events and the ability to use this memorial information as a conditional cue to discriminate the choice trials in which the left arm was correct from those trials in which the right arm was correct. Rats of different ages were first trained to criterion on the win/shift version of the conditional-spatial discrimination. Once the subject reached criterion on the initial problem, its memory for the information acquired on the forced run was further challenged by being tested over a range of delay intervals separating the forced and choice runs.

\section{Method}

\section{Subjects}

The subjects were male and female Long-Evans rats obtained from the breeding colony at the University of Colorado (see Moye \& Rudy, 1985, for a description of colony management). The rats were 21,28 , or 38 days old at the start of training. The dams remained with the 21-day-olds until the experiment was completed. Otherwise, the litters were weaned when the pups were 25 days old.

\begin{abstract}
Apparatus
The rats were trained to escape from water in a T-maze constructed of transparent Plexiglas. The stem and arms of the maze were each $30 \mathrm{~cm}$ long, $15 \mathrm{~cm}$ wide, and $65 \mathrm{~cm}$ deep. The water level was approximately $25 \mathrm{~cm}$ deep, and the water was maintained at $26^{\circ} \mathrm{C}$. Each arm could be blocked by a clear Plexiglas removable insert. An escape platform $(12 \times 12 \mathrm{~cm})$ was placed in one or the other arm $1 \mathrm{~cm}$ below the water's surface. To ensure that the platform was not visible, the water was clouded by nontoxic white Crayola watercolor paint. The maze was set on a table approximately $1 \mathrm{~m}$ above the floor in a $2.8 \times 2.7 \times 2.5 \mathrm{~m}$ room. Objects in the room included a black storage cabinet located $0.5 \mathrm{~m}$ behind the stem of the maze, an aquarium on a table about $1.8 \mathrm{~m}$ to the right of the maze, and an experimenter, who always stood on the right side of the maze. The walls on either side of the maze contained one-way mirrors. The distance between the left wall and left arm of the maze was about $0.5 \mathrm{~m}$. The room was illuminated by two $100-\mathrm{W}$ incandescent bulbs, one located in a ceiling fixture $90 \mathrm{~cm}$ directly above the maze and the other in a ceiling fixture located $95 \mathrm{~cm}$ to the right of the maze.
\end{abstract}

\section{Procedure}

Training. Prior to the first trial of each session, the subject was placed once, for $15 \mathrm{sec}$, on the platform in each arm. A trial con- sisted of a forced run and a choice run. On the forced run, one arm of the T-maze was blocked and the escape platform was placed in the unblocked arm. On the choice run, neither arm was blocked and the escape platform was placed in the arm that had been blocked on the forced run. The forced run began when the subject was placed in the stem and ended when the pup climbed onto the escape platform in the unblocked arm. Ten seconds after the subject escaped, it was returned to its holding cage while the maze was prepared for the choice run. This preparation took about $10 \mathrm{sec}$. The subject then was given its choice run. If the subject entered the correct arm, it was allowed to climb onto the platform and then was immediately returned to the holding cage. If the subject chose the wrong arm, it was trapped in that arm for $15 \mathrm{sec}$ before being returned to the holding cage.

Three subjects were rotated through this trial sequence so that each subject's intertrial interval was approximately $120 \mathrm{sec}$. Determination of which arm was blocked on the forced run was random with the restriction that the same arm could not be blocked for more than 3 trials in succession. Each subject received 30 such trials a day, unless it reached a criterion of 9 correct choices out of 10 trials, in which case it received 5 additional trials and its training was terminated.

Testing. Testing occurred on the day following the subject's criterion run. First, the subject received an additional 30 trials of overtraining. After a 2 -h rest it received 3 more trials, after which the formal test protocol was administered. The subject initially received 7 trials in which the forced run/choice run interval was 8-10 sec. These trials were used to calculate the subject's pre-test-trial choice accuracy. Seven test trials were then administered. For independent groups of subjects the forced-run/choice-run interval was 30 , 60 , or $180 \mathrm{sec}$. At the completion of the 7 test trials, each subject was again given 7 trials, for which the delay interval was reduced to 8-10 sec to establish its post-test-trial choice accuracy. The intertrial interval throughout testing was $120 \mathrm{sec}$. Any subject that did not choose correctly on at least 4 of the 7 pretest choice trials was not tested. This culling was done to ensure that the subjects at each age and test-delay condition were performing at the same level prior to the test. Two 21-day-olds and one 38-day-old had to be excluded from the experiment for failing to meet this criterion. These subjects were subsequently replaced.

\section{Subject Assignment}

At each test age, independent sets of 6 subjects were tested at $30-, 60-$, and 180-sec delay intervals. There were nine independent groups of subjects. At each age, six different litters contributed 1 subject each to each group.

\section{Training}

\section{Results}

The three subgroups tested at each age did not differ on the trials-to-criterion measure. The mean trials to criterion were 88,97 , and 80 for the 21-day-old subgroups, 64,53 , and 68 for the 28-day-old subgroups, and 49, 40, and 43 for the 38-day-old subgroups. Collapsed across the three subgroups at each age (see Figure 1), however, the mean number of trials to reach criterion was agedependent $[F(2,51)=12.21, p<.001]$. Newman-Keuls post hoc analyses revealed that each age group differed significantly from the others $(p<.05)$.

\section{Testing}

The average test ages (in days) were 24.8, 24.6, and 24.3 for the 21-day-old subgroups, $31,30.5$, and 31 for the 28-day-old subgroups, and $40.3,40.1$, and 40.1 for 


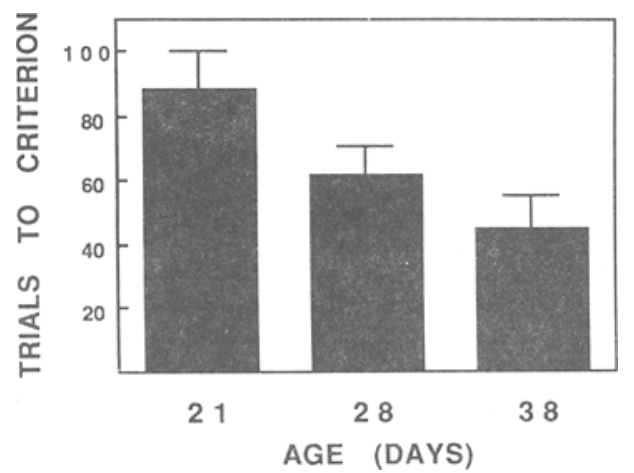

Figure 1. Mean number of trials to criterion as a function of age. Bars indicate standard errors of the mean.

the 38-day-old subgroups. Hereafter, the three age levels will be referred to as the 25-, 31-, and 40-day-olds when reference is made to the pups' ages on the test days.

Figure 2 clearly reveals that the effect of increasing the delay between the forced run and choice run was agedependent. At the 30-sec delay, there were no differences in choice accuracy among the different age groups. At the 60 -sec delay, the performance of the youngest subjects deteriorated, whereas choice accuracy of the 31- and 40-day-old animals remained high and did not differ from pre- and post-test-trial baselines. At the 180 -sec delay, the performance of both the 25- and 31-day-old subjects deteriorated, both in comparison with their own pre- and post-test-trial baselines and in comparison with the performance of the 40-day-old subjects. In the statistical evaluation of the test results, the data summarized in the three panels of Figure 2 were each subjected to a mixed factors $3 \times 3$ (age $\times$ test trials) analysis of variance. When the delay was $30 \mathrm{sec}$, age, test trial, and their interaction were not reliable. At both the 60- and 180-sec delays, however, there was a significant age $\times$ test trial interaction $[F(4,30)=3.22, p<.05$, and $F(4,30)=3.96, p<$ .05 , respectively]. Analysis of the interaction at the $60-\mathrm{sec}$ delay indicated that there were reliable test trial differences for the 25 -day-olds $[F(2,15)=8.50, p<.01]$ but not for the 31- and 40-day-olds. An analysis of the interaction at the $180-\mathrm{sec}$ delay indicated that there were reliable test trial differences for both the 25- and 31-day-olds $[F(2,15)=10.20, p<.01$, and $F(2,15)=37.44, p<$ .01 , respectively].

\section{Discussion}

Young rats were impaired relative to older rats in solving the win/shift conditional-spatial discrimination. The 21-day-olds required approximately twice as many trials to reach criterion as did the 38-day-olds.

Although the number of trials that the pups took to reach criterion was age-dependent, pups at every age eventually performed at a similar level when the delay interval separating forced runs and choice runs was relatively brief (10-30 sec). Nevertheless, when the delay interval was increased, the choice trial performance of the younger animals was impaired. The 25-day-olds' performance deteriorated when the delay was $60 \mathrm{sec}$, and the 31-day-olds' performance was poor when the interval was $180 \mathrm{sec}$. This finding might simply reflect an age-dependent difference in the strength of the memory representation established on the forced run. The representation can endure for $180 \mathrm{sec}$ when the animal is 40 days old, but persists for fewer than $60 \mathrm{sec}$ when the animal is only 25 days old.

The memory-trace hypothesis, however, must be weighed against several other possibilities. For example, one might argue that the age-related memory effect may represent nothing more than the fact that we had not

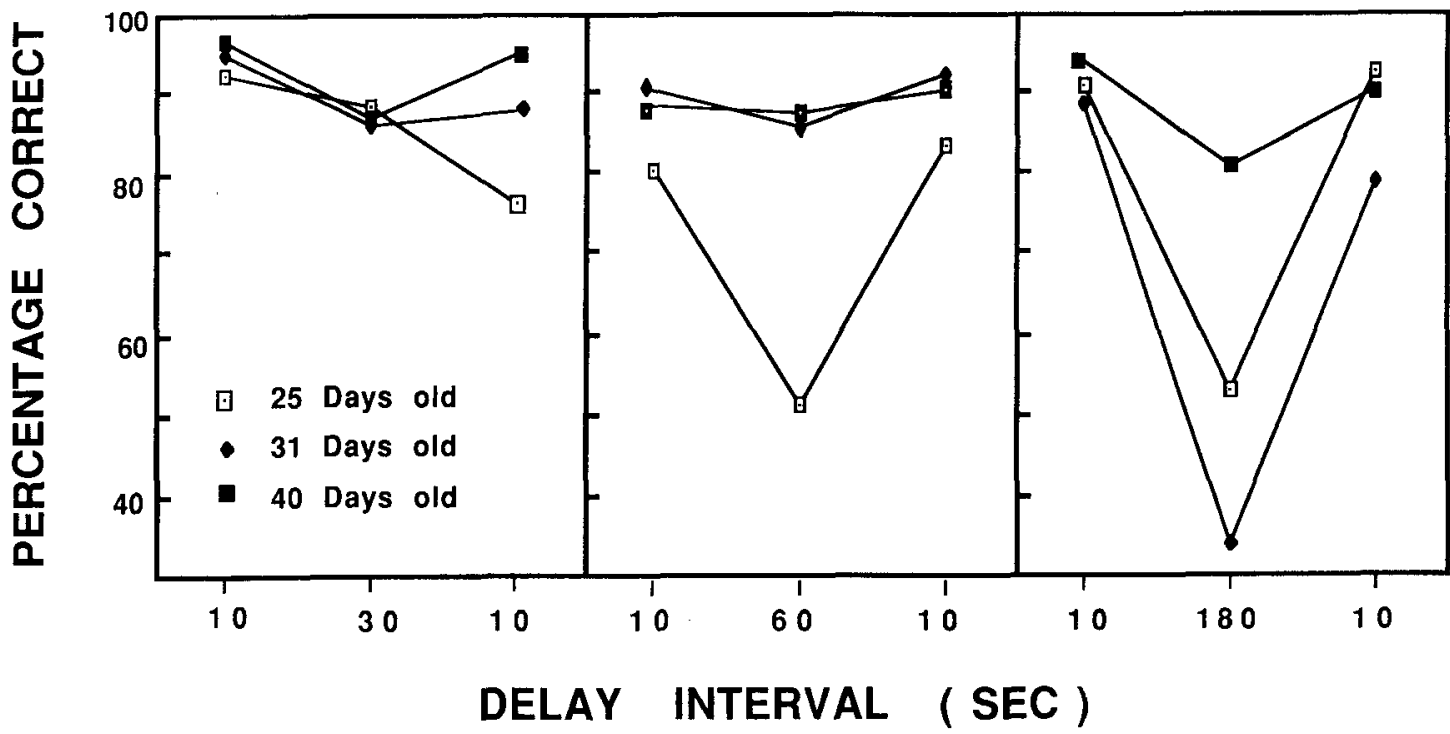

Figure 2. Mean percentage of correct choices for subjects of different ages as a function of the delay interval. The two 10-sec delays associated with each panel represent the subjects' pre- and post-test-trial choice accuracy (see Experiment 1 Method). 
equated the different-age subjects for the degree of original learning of the problem. The younger pups simply may be more sensitive to the increasing forced-run/choice-run interval than the older subjects because they had not learned the discrimination as well. There are, however, data that argue against this hypothesis. Recall that on the day following the session in which the animal reached criterion, it received an additional 30 trials of overtraining. If there were age-related differences in the strength of initial learning, then one would expect that $24 \mathrm{~h}$ later the younger animals would make more errors during overtraining than would the older animals. This was not the case. As can be seen in Figure 3, there was no difference among the groups on the number of errors made during overtraining. There is thus no reason to suspect that there were age-related differences in original learning that would influence performance on the memory test.

Another alternative to the memory-trace hypothesis is the possibility that the young rat's problem may not relate so much to its ability to sustain a memory representation of the forced run as it does to its ability to deal with the sources of retroactive and proactive interference that are potentially present (see Spear, 1979). To perform correctly on the choice trial, the animal must discriminate the memory of the immediately preceding forced run from the memories generated by earlier forced runs and choice runs (proactive interference). It must also be able to protect the trial-relevant forced-run memory from the potentially disruptive effects of events experienced during the delay interval (retroactive interference). Viewed from this perspective, the age-related difference that appeared when the delay interval was increased might have been due in part to maturational differences in the rats' memorymaintenance processes (Grant, 1982; Maki, 1981; Wagner, Rudy, \& Whitlow, 1973). Older rats might be more proficient in either selectively maintaining the relevant forced-run memory or selectively forgetting the memories generated by an irrelevant forced run or choice run.

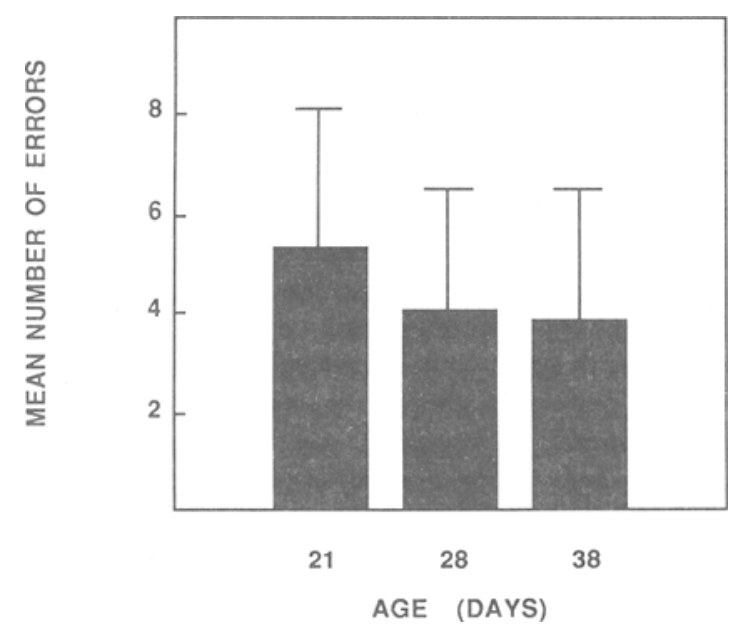

Figure 3. The mean number of errors subjects at each age made during the 30 trials of overtraining during Experiment 1.
There is nothing in the present data that provides a basis for discriminating between the trace-decay and memory-maintenance alternatives. It is of some interest, however, that Bachevalier and Mishkin (1984) have reported data suggesting that young monkeys' recent memories are more vulnerable to disruption by retroactive experiences than are those of older monkeys. In the recognition-memory paradigm used by these researchers, the subject was shown a novel visual object (sample) and then given a choice trial that included the now familiar object and a novel object. The correct response on the choice trial was the novel object. Once the choice rulc was acquired, the delay interval between the sample and choice trial was varied from 0 to $120 \mathrm{sec}$. The choice performance of monkeys ranging in age from 7 months to 3 years was not affected by the increase in the delay interval. When the monkeys were exposed to up to $10 \mathrm{sam}-$ ple stimuli before a choice trial, however, choice performance became an age-related function of the number of sample stimuli. The performance of the oldest animals was unaffected by the number of sample stimuli, whereas the performance of the youngest monkeys was seriously impaired.

The age-related differences in acquisition seen in the present study could thus be the result of a variety of factors. For example, there may be maturational differences in (1) the processes that enable the animals to discriminate the two choices, (2) the response tendencies the animals bring to the task, (3) the animals' ability to remember the information acquired on the forced run, or (4) the processes that enable the animal to integrate the information acquired on the forced run with the information associated with the choice run. Experiments 2 and 3 addressed some of these alternatives.

\section{EXPERIMENT 2}

One explanation of the acquisition differences seen in Experiment 1 is that there may be differences in the response tendencies the different-aged subjects bring to the task that might either compete with or facilitate the correct response on the choice trial. For example, the win/shift problem employed in the first experiment required that the animals choose the arm that was blocked on the forced run. The older animals might reach criterion on this problem more quickly than younger animals either (1) because the older animals have a stronger predisposition to spontaneously alternate, that is, to choose the arm that was blocked on the forced run, or (2) because the younger animals have a stimulus bias, a strong predisposition to choose the arm chosen on the forced run. A tendency to spontaneously alternate might facilitate the older animals' reaching criterion on a win/shift problem, and a stimulus bias would interfere with the young animals' reaching criterion. Thus, even though there may be no maturational differences in the learning and memory processes mediating performance in the win/shift task, the younger animals might still require more trials to reach 
criterion because of the age-related differences in the response predispositions the animals bring to the task.

The purpose of Experiment 2 was to determine the response tendencies of the different-aged subjects uncontaminated by any reinforcement contingencies. As in Experiment 1, each trial consisted of a forced run to one arm followed by a choice run. On the choice trial, however, an escape platform was placed in each arm. Thus there was no contingency between platform location on the forced and choice runs.

The outcome of this experiment seemed potentially relevant to several of the alternative explanations of the first experiment. For example, suppose that the young animals did, in fact, display a relatively strong win/stay strategy. This outcome would provide support for the competing response explanation and also direct evidence (1) that the youngest animals can discriminate between the choice alternatives and (2) that they can remember the outcome of the forced run. This would weaken the hypotheses that attribute the acquisition differences obtained in Experiment 1 to maturational differences in the processes that enable the animal to discriminate the choices and to remember the outcome of the forced run.

Method
Training
With two exceptions, the procedure used in this experiment was
identical to the procedure of Experiment 1 . Long-Evans rats, 21 ,
28 , and 38 days old ( $n=6$ at each age) at the start of the experi-
ment, received 30 trials a session, where a trial consisted of both
a forced run and a choice run. One difference between the two ex-
periments was that while only one arm contained a platform in Ex-
periment 1 , on the choice run of Experiment 2 an escape platform
was placed in each arm of the maze. The other difference lay in
the number on trials each animal received. In Experiment 1 , each
subject was trained until it reached criterion. In Experiment 2 , there
was no correct choice or criterion to be reached. In this experi-
ment, the number of training trials was set by the mean number
of trials the subjects in each age group took to reach criterion in
Experiment 1 . The numbers of trials were 105 , 75 , and 60 , respec-
tively, for the $21-, 28-$, and 38 -day-olds. As in Experiment 1,6
subjects in each group were drawn from six litters.

\section{Dependent Variables}

We determined the stimulus bias and response bias of each subject. Stimulus bias was calculated by dividing training into blocks of 15 trials and calculating the percentage of trials on which the subject chose the same arm on the choice trial as it was forced to on the forced run. It should be noted that the animal's tendency to spontaneously alternate is the inverse of its stimulus bias. The subject's response bias also was calculated over blocks of 15 trials. For each trial block, we determined which arm the subject chose most frequently. The percentage of trials the subject went to this arm then served as the basic measure. Note that this procedure allows for the possibility that the animal's response bias could shift during the course of training.

\section{Results}

Figure 4 (top panel) presents the stimulus bias data that reflect the animal's tendency to return to the unblocked arm of the forced arm. Note that during the initial 30 train-
STIMULUS BIAS

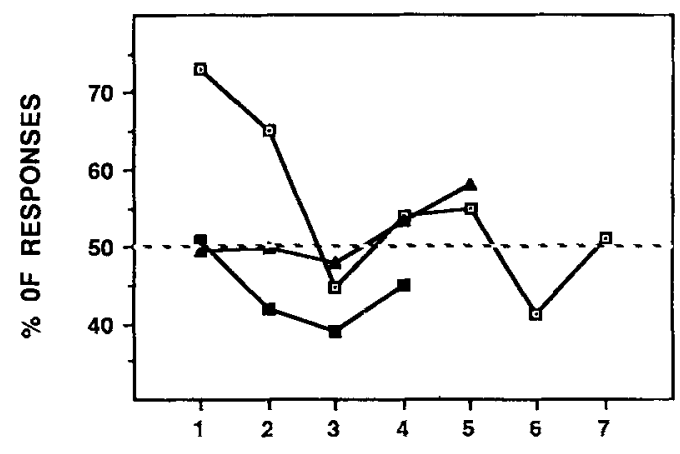

RESPONSE BIAS

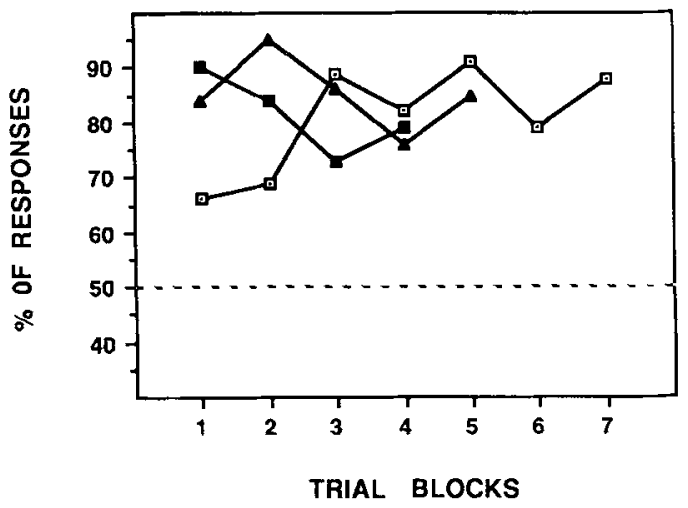

\begin{tabular}{lll}
\hline 21 D.O. & -280.0 \\
\hline
\end{tabular}

Figure 4. The percentage of trials on which the different-aged animals displayed a stimulus bias (top panel) and the percentage of trials on which they displayed a response bias (bottom panel) during Experiment 2.

ing trials there were age-related differences in this measure. The 21-day-olds displayed a stimulus bias over the first 30 trials of training but thereafter were at chance with respect to returning to the forced arm. The older animals, however, never displayed a stimulus bias or a tendency to spontaneously alternate. Throughout training, their performance on the choice trial was independent of which arm it was forced to on the forced run. This description of the data was supported by a two-way analysis of variance performed on the first 4 trial blocks of the data presented in Figure 4. It revealed a significant effect of age $[F(2,15)=9.3, p<.01]$ and trial block $[F(6,45)$ $=4.4, p<.01]$, but the age $\times$ trial block interaction was not significant $[F(45)=1.89]$. Post hoc comparisons revealed that the 21 -day-olds differed $(p<.05$, Newman-Keuls test) from the 38-day-olds. The 28 - and 38-day-olds did not differ on this measure.

Figure 4 (bottom panel) presents the response-bias data for the different-aged animals. Again, there were agerelated differences. In this case, the 28- and 38-day-olds 
initially displayed a stronger tendency to consistently choose one arm than did 21-day-olds. With continued training, however, the 21-day-olds also developed a response bias similar to that of the older pups. These conclusions were supported by a two-way repeated measures analysis of variance that revealed a significant age $\times$ trial blocks interaction $[F(2,15)=4.23, p<.05]$. An analysis of this interaction indicated that there were significant differences among the groups on both Trial Blocks 1 and 2 . Post hoc analyses indicated that the response bias of the 21-day-olds was significantly weaker $(p<.05$, Newman-Keuls test) than that of either the 28- or 38-dayolds on both Trial Blocks 1 and 2 . There was no difference between the 28- and 38-day-olds.

\section{Discussion}

These results are especially informative. First, the fact that the 21-day-olds displayed a relatively strong win/stay strategy during initial training supports the hypothesis that an incompatible stimulus bias may have contributed to their slow rate of acquisition on the win/shift problem in Experiment 1 . The fact that the 21-day-olds displayed an initial stimulus bias is also important because, for this result to occur, the pups had to be able to (1) discriminate the two-choice alternatives and (2) remember the place or response they had made on the forced run. It thus seems unlikely that the 21-day-olds' relatively slow rate of acquisition in Experiment 1 was a result of maturational differences in the processes mediating their ability to discriminate between the two arms of the maze or their ability to remember the outcome of the forced run.

The 28- and 38-day-old subjects used the same strategy in Experiment 2. Animals at both ages displayed a strong response bias throughout training and no tendency to spontaneously alternate. It is therefore unlikely that the superior performance of older animals on the win/shift problem was the result of a predisposition to spontaneously alternate. Moreover, given this pattern of results, it seems unlikely that the difference between 28 - and 38day-olds observed in Experiment 1 can be attributed to preexisting response strategies they bring to the task.

\section{EXPERIMENT 3}

The 21-day-olds' initial display of a strong stimulus bias in Experiment 2 is especially interesting. It suggests that, in solving a win/stay problem, the 21-day-olds might reach criterion in the same number of trials as, or in a fewer number of trials than, the older animals. The purpose of this experiment was to compare these different-aged pups on both the win/shift problem used in Experiment 1 and a win/stay version of the problem. In the win/stay problem, the animal also received both a forced run and a choice run, and the correct response was conditionally related to the outcome of the forced run. In this case, however, the animal had to choose the arm to which it had been forced on the forced run. Note that the stimulus bias that presumably worked against the 21 -day-olds when solving the win/shift problem in Experiment 1 should enhance their performance, relative to that of the older animals, on the win/stay problem.

\section{Method}

Male and female Long-Evans rats, 21, 28, or 38 days old, were trained on one of two problems. Half the subjects at each age were required to solve the win/shift problem used in Experiment 1; the other half were required to solve a win/stay version. Training was exactly as in Experiment 1 for pups required to solve the win/shift problem. For these pups, the correct response on the choice run was conditionally related to the outcome of the forced run: the subject had to choose the arm that was blocked on the forced run. For pups in the win/stay condition, the correct arm was the arm that had been unblocked on the forced run. Otherwise, all aspects of training were identical for all pups. Again, the 6 subjects in each condition were drawn from six litters.

\section{Results}

Figure 5 presents the mean number trials subjects at each age required to solve both the win/shift and win/stay problems. It reveals two points. First, pups at each age required fewer trials to solve the win/stay problem than they did to solve the win/shift problem. Second, younger pups required more trials to solve these problems than did older pups. The results of a two-way analysis of variance were consistent with this description of the data. It revealed a main effect of problem $[F(1,30)=15.6, p<$ $.01]$ and age $[F(2,30)=28.9, p<.01]$, but the interaction of these two variables was not reliable. Post hoc comparisons revealed that all age groups were reliably different $(p<.05$, Newman-Keuls test).

\section{Discussion}

Although the 21-day-olds solved the win/stay problem in fewer trials than they did the win/shift problem, they required more trials to solve the win/stay problem than

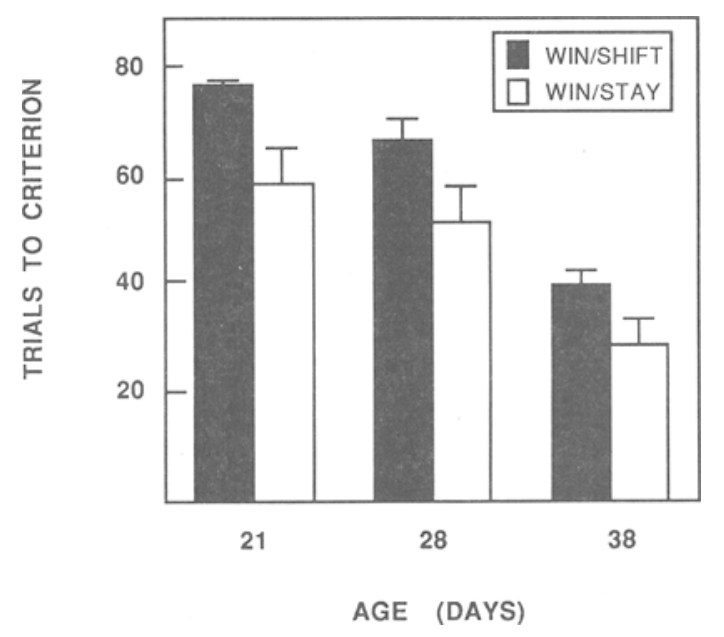

Figure 5. The mean number of trials to criterion for the different age groups on the win/stay and win/shift problems of Experiment 3. Bars represent standard errors of the mean. 
did the older animals. This finding argues strongly against the hypothesis that the 21-day-olds were impaired on the win/shift problem in Experiment 1 and in this experiment because they had to learn to overcome a stimulus bias. If this explanation were correct, then the 21-day-olds should have required no more trials to reach criterion on the win/stay problem than older animals.

The finding that the 21-day-olds required more trials to solve the win/stay problem than did the older subjects, even though they had a stimulus bias that placed them in contact with the reinforcement contingencies, suggests that they were insensitive to the conditional relationship that exists between the outcome of the forced run and correct choice.

We are not the only researchers to report that despite the fact that it may have a memory for a previous trial outcome, the young animal is relatively insensitive to the relationship of this memory to the contingencies of the next trial; Gittes et al. (in press) reported a similar finding in an appetitive conditional-spatial discrimination task, and Bachevalier and Mishkin (1984) reported a comparable result in their developmental study of the rhesus monkey's acquisition of the stimulus recognition memory problem. Recall that in the latter (see discussion of Experiment 1), the monkey was required to learn to choose the novel item of a pair of objects. Three-month-olds were markedly impaired in learning to solve this problem, even though they displayed an initial predisposition to choose the novel object. Evidently being in contact with the correct reinforcement contingencies is not a sufficient condition for either the immature rat or the monkey to learn the relationship between its memory for a trial outcome and the behavioral contingencies of the next trial.

The results of this experiment, in fact, argue against attributing the age-related differences observed in either the win/stay or the win/shift problem to any preexisting systematic stimulus or response bias. Simply put, any agerelated stimulus or response bias that would facilitate or interfere with solving one problem (e.g., the win/shift problem) should have exactly the opposite effect on the other problem (e.g., the win/stay problem). The effect of age on trials to criterion, however, was independent of the problem.

It should also be noted that our finding that, independent of age, the rat solved the win/stay problem more rapidly than it solved the win/shift version of the aquatic T-maze contrasts with what others have found in an appetitive version of the same task. The typical finding in the appetitive version is that rats learn the win/shift version more rapidly than they do the win/stay versions (Olton \& Schlosberg, 1978; Stanton, Thomas, \& Brito, 1984). It is also true that the rat displays a predisposition to spontaneously alternate that is independent of the reward contingencies in the appetitive situation (Olton \& Schlosberg, 1978), whereas we found no evidence of spontaneous alternation at any age in the aquatic T-maze.

\section{GENERAL DISCUSSION}

These experiments revealed that there are ontogenetic differences both in the learning processes that enable the rat to solve conditional-spatial discrimination problems and in the short-term-memory processes that enable the animal to maintain the conditional information that is needed to choose correctly on the choice run.

Maturation of the memory maintenance processes, in fact, appears to continue well after the development of acquisition processes that enable the animal to solve conditional-spatial problems. Although the latter finding is novel for conditional-spatial discriminations, the general finding of improved short-term memory that occurs with age is not without precedent. As we have noted, Moye and Rudy (1987a) recently reported a similar finding using a Pavlovian trace-conditioning paradigm. In addition, Stanton (1982) reported an age-related difference in rats that were learning a single-alternation pattern of rewarded and nonrewarded trials that depended on the length of the interval separating the rewarded and nonrewarded trials. He found that 14-day-old rats responded to the reward pattern even when the interval between trials was $30 \mathrm{sec}$. In contrast, 11-day-old pups responded to the pattern only when the interval was $8 \mathrm{sec}$. As noted above, Bachevalier and Mishkin (1984) reported substantial maturation of the short-term-memory processes mediating the monkey's performance on the stimulus-recognition memory task.

The age-related differences observed in the present experiments are likely to be related to maturational differences in some components of the neural systems that contribute to performance. It has long been appreciated that maturation of the hippocampal formation may be importantly related to behavioral development (Altman, Bruner, $\&$ Bayer, 1973), and maturational differences in the hippocampal formation may contribute to the acquisition differences we have observed. This hypothesis is supported by several other findings. Aggleton, Hunt, and Rawlins (1986, Experiment 3), for example, reported that rats with hippocampal damage were unable to learn the win/stay version of an appetitive conditional-spatial discrimination problem. Similarly, Stanton et al. (1984) reported that rats with septohippocampal damage were impaired on both the win/stay and win/shift versions of this task. Thus, some aspects of the hippocampal formation appear to be essential for the rat to make conditionalspatial discriminations.

The suggestion that the age-related behavioral differences we report could be related to the development of the hippocampus is consistent with other evidence. For example, in the rat there is substantial postnatal maturation of the hippocampus up to and beyond the 4th postnatal week (Altman \& Das, 1965). Synaptic density in both the dentate gyrus and hippocampal formation does not reach adult levels until Day 25 (Crain, Cotman, Taylor, \& Lynch, 1973; Pokorny \& Yamamoto, 1981), and adult 
patterns of metabolic activity are not observed until Day 30 (Meibach, Ross, Cox, \& Glick, 1981). By other measures, such as complex spine formation in the dentate gyrus (Cotman, Taylor, \& Lynch, 1973) and development of the distal lateral and preterminal branches of the CA1 pyramidal neurons (Pokorny \& Yamamoto, 1981), the hippocampus continues to mature up to about the 7 th postnatal week.

The possibility that maturational differences in the prefrontal cortex contribute to the ontogenetic effects we observed should also be considered. It has been found, in a variety of species, that damage to subdivisions of this brain region have resulted in impaired performance in spatial alternation and delayed reaction performance (see Rosenkilde, 1983, and Kolb, 1984, for reviews). Most relevant to the present data are the findings that damage to the rat's medial prefrontal lobe impairs spatial reversal learning, delayed spatial reaction performance (Kolb, Nonneman, \& Singh, 1974), place learning in the Morris water task (Kolb, Sutherland, \& Whishaw, 1983; Sutherland, Kolb, \& Whishaw, 1982), and contingent spatial alternation (Larson \& Divac, 1978; Thomas \& Brito, 1980; Wikmark, Divak, \& Weiss, 1973).

Maturation of the central cholinergic systems (Douglas, 1975) also should be considered for its contribution to behavioral development in conditional-spatial discrimination. Evidence for this hypothesis comes from several sources. First, Hepler, Olton, Wenk, and Coyle (1985) found that combined lesions of the nucleus basalis and medial septal area impair the rat's performance in an appetitive win/stay conditional-spatial discrimination. This impairment suggests that the cholinergic systems are important for tasks in which performance depends on the subject's memory for recent events (see also Aigner \& Mishkin, 1986; Wirsching, Beninger, Jhamandas, Boegman, \& El-Defrawy, 1984). Second, Coyle and Yamamura (1976), Johnston (1985), and Telang and Enna (1985) found that the central cholinergic systems have a protracted developmental time course in the rat. Third, Rauch and Raskin (1984) reported that the workingmemory component of the spatial eight-arm radial maze is impaired by a cholinergic blockade. Fourth, Moye and Rudy (1987b) provided evidence linking the maturation of the cholinergic system with the development of the short-term-memory system that mediates Pavlovian trace conditioning (see the introduction section above). Specifically, they reported that (1) a blockade of the cholinergic system by scopolamine prevents older animals from conditioning when a visual CS is temporally separated from US occurrence but does not prevent conditioning when the CS terminates with US occurrence, and (2) young subjects that would normally fail to condition when the CS and US are temporally separated strongly condition if they were administered the cholinergic agonist physostigmine before the conditioning session.

This line of argument and evidence suggests that the developmental changes uncovered in the present experiment might depend, at least in part, on maturation of the central cholinergic system. This hypothesis would gain strong support if the administration of cholinergic agonists such as physostigmine could be shown to improve the young rat's choice performance following long delays in the delayed-alternation task employed in the present investigation.

We conclude by briefly discussing the novel aquatic spatial discrimination task that we developed especially for these experiments. In our opinion, it has several advantages over alternative procedures one could use for this purpose. A primary advantage, of course, is that one does not need to food-deprive the animal and therefore worry about the effects of food deprivation on normal growth and development. We have now used escape from water as the motivating stimulus in three different tasks: (1) to study the development of place learning using Morris's (1981) tasks (Castro \& Rudy, 1987; Rudy \& Paylor, in press; Rudy \& Stadler-Morris, 1987; Rudy et al., 1987), (2) to study the development of brightness discrimination learning (Rudy \& Castro, 1987), and (3) to study the development of conditional-spatial discrimination learning and memory (present studies). It is our experience that escape from water provides an ideal motivator for animals from about 16-17 days of age through adulthood. The rat is an excellent swimmer, adjusts rapidly to the water, and does not appear to get overly excited. Thus, we highly recommend these tasks to researchers interested in further advancing our understanding of the development of learning and memory.

\section{REFERENCES}

Aggleton, J. P., Hunt, P. R., \& Rawlins, J. N. P. (1986). The effects of hippocampal lesions upon spatial and non-spatial tests of working memory. Behavioral Brain Research, 19, 133-146.

AIgNer, T. G., \& Mishkin, M. (1986). The effects of physostigmine and scopolamine on recognition memory in monkeys. Behavioral \& Neural Biology, 45, 81-87.

Altman, J., Bruner, R. L., \& Bayer, S. A. (1973). The hippocampus and behavioral maturation. Behavioral Biology, 8, 557-596.

Altman, J., \& DAs, G. D. (1965). Autoradiography and histological evidence of postnatal neurogenesis in rats. Journal of Comparative Neurology, 124, 319-336.

Bachevalier, J., \& Mishkin, M. (1984). An early and a late developing system for learning and retention in infant monkeys. Behavioral Neuroscience, 98, 770-778.

Castro, C. A., \& Rudy, J. W. (1987). Early-life malnutrition selectively retards the development of distal- but not proximal-cue navigation. Developmental Psychobiology, 20, 521-537.

Cottman, C., Taylor, D., \& LyNCh, G. (1973). Ultrastructural changes in synapses in the dentate gyrus of the rat. Brain Research, 63, 205-213.

Coulter, X., Collier, A. C., \& Campbell, B. A. (1976). Long-term retention of early Pavlovian fear conditioning in infant rats. Journal of Experimental Psychology: Animal Behavior Processes, 2, 48-56.

Coyle, J. T., \& Yamamura, H. I. (1976). Neurochemical aspects of the ontogenesis of cholinergic neurons in the rat brain. Brain Research, 118, 429-440.

Crain, B., Cotman, C., Taylor, D., \& Lynch, G. (1973). A quantitative electron microscopic study of synaptogenesis in the dentate gyrus of the rat. Brain Research, 63, 195-204.

Douglas, R. J. (1975). The development of hippocampal function: Implications for theory and for therapy. In R. Isaacson \& K. Pribram 
(Eds.), The hippocampus (Vol. 2, pp. 327-361). New York: Plenum Press.

Gittes, A. G., Stark, H., Arnold, C., Geter, B., Frazier, D., \& Olton, D. A. (in press). Emergence of choice strategies in the rat: Shift-stay differentiation precedes win-lose differentiation. Animal Learning \& Behavior.

Grant, D. S. (1982). Stimulus control of information processing in rat short-term memory. Joumal of Experimental Psychology: Animal Behavior Processes, 8, 154-164.

Hepler, D. J., Olton, D. S., Wenk, G. L., \& Coyle, J. T. (1985). Lesions in nucleus basalis magnocellularis and medial septal area of rats produce qualitatively similar memory impairments. Journal of Neuroscience, 5, 866-873.

Hyson, R. L., \& RUDY, J. W. (1984). Ontogeny of learning: II. Variation in the rat's reflexive and learned responses to acoustic stimulation. Developmental Psychobiology, 17, 263-283.

Johanson, I. B., \& HaLL, W. G. (1982). Appetitive conditioning in neonatal rats: Conditioned orientation to a novel odor. Developmental Psychobiology, 15, 379-397.

Johanson, I., \& Teicher, M. H. (1980). Classical conditioning of an odor preference in 3-day-old rats. Behavioral \& Neural Biology, 29, 132-136.

Johnston, M. V. (1985). Neurotransmitters. In R. C. Wiggins, D. W. McCandless, \& S. J. Enna (Eds.), Developmental neurochemistry (pp. 193-224). Austin: University of Texas Press.

Kolb, B. A. (1984). Functions of the frontal cortex of the rat: A comparative review. Brain Research Reviews, 8, 64-98.

Kolb, B. A., Nonneman, A. J., \& Singh, R. K. (1974). Double dissociation of spatial impairments and perseveration following selective prefrontal lesions in rats. Journal of Comparative \& Physiological Psychology, 87, 772-780.

Kolb, B. A., Sutherland, R. S., \& Whishaw, I. Q. (1983). A comparison of the contributions of the frontal and parietal association cortex to spatial localization in rats. Behavioral Neuroscience, 97, 13-27.

LARSON, J. K., \& DivaC, I. (1978). Selective ablations within the prefrontal cortex of the rat and performance of delayed alternation. Physiological Psychology, 6, 15-17.

MAKI, W. S. (1981). Directed forgetting in pigeons. In N. E. Spear \& R. R. Miller (Eds.), Information processing in animals: Memory mechanisms. Hillsdale, NJ: Erlbaum.

Meibach, R. C., Ross, D. A., Cox, R. D., \& Guick, S. D. (1981). The ontogeny of hippocampal energy metabolism. Brian Research, 204, 431-435.

Morris, R. G. M. (1981). Spatial localization does not require the presence of local cues. Learning \& Motivation, 12, 239-260.

MoYe, T. B., \& RUDY, J. W. (1985). Ontogenesis of learning: VI. Learned and unlearned responses to visual stimulation in the infant hooded rat. Developmental Psychobiology, 18, 395-409.

MoYE, T. B., \& RUDY, J. W. (1987a). Ontogenesis of trace conditioning in young rats: Dissociation of associative and memory processes. Developmental Psychobiology, 20, 405-414.

MOYE, T. B., \& RUDY, J. W. (1987b). Visually mediated trace conditioning in young rats: Evidence for cholinergic involvement in the development of associative memory. Psychobiology, 15, 128-137.

Olton, D. S., \& Schlosberg, P. (1978). Food-searching strategies in young rats: Win-shift predominates over win-stay. Journal of Comparative \& Physiological Psychology, 92, 609-618.

PoKoRny, J., \& YAMAмоTo, T. (1981). Postnatal ontogenesis of hippocampal CAl area in rats: I. Development of dendritic arborization in pyramidal neurons. II. Development of ultrastructure in stratum lacunosum and moleculare. Brain Research Bulletin, 7, 113-130.

RaUCH, S. L., \& RASKIN, L. A. (1984). Cholinergic mediation of spatial memory in the preweanling rat: Application of the radial arm maze paradigm. Behavioral Neuroscience, 98, 35-43.

RoSENKILDE, C. E. (1983). Functions of the prefrontal cortex. Acta Physiologica Scandinavica, Supplement 514, 1-58.
Rudy, J. W., \& Castro, C. A. (1987). A developmental analysis of brightness discrimination learning in the rat: Evidence for an attentional deficit. Psychobiology, 15, 79-86.

Rudy, J. W., \& Cheatle, M. D. (1977). Odor-aversion learning by neonatal rats. Science, 198. 845-846.

Rudy, J. W., \& ChEATLE, M. D. (1979). Ontogeny of associative learning: Acquisition of odor aversions by neonatal rats. In N. E. Spear \& B. A. Campbell (Eds.), Ontogeny of learning and memory (pp. 155187). Hillsdale, NJ: Erlbaum.

Rudy, J. W., \& Hyson, R. L. (1984). Ontogenesis of learning: III. Variation in the rat's differential reflexive and learned responses to sound frequencies. Developmental Psychobiology, 17, 285-300.

Rudy, J. W., \& PAYlor, R. (1987). The development of interocular equivalence of place learning in the rat requires convergence sites established prior to training. Behavioral Neuroscience, 101, 732-734.

Rudy, J. W., \& Stadler-Morris, S. (1987). The development of interocular transfer by rats trained on a distal-cue navigation task. Behavioral Neuroscience, 101, 141-143.

Rudy, J. W., Stadler-Morris, S., \& Albert, P. (1987). Ontogeny of spatial navigation behaviors in the rat: Dissociation of "proximal" and "distal"-cue-based behaviors. Behavioral Neuroscience, 101, 62-73.

SPEAR, N. E. (1979). Memory storage factors leading to infantile amnesia. In G. H. Bower (Ed.), The psychology of learning and motivation (Vol. 13, pp. 91-154). New York: Academic Press.

SPEAR, N. E., \& KucharsKi, D. (1985). Ontogenetic differences in stimulus selection during conditioning. In R. Kail \& N. E. Spear (Eds.), Comparative perspectives on the development of memory (pp. 227-252). Hillsdale, NJ: Erlbaum.

Stanton, M. E. (1982). Performance of 11- and 14-day-old rats on a working memory problem. Behavioral \& Neural Biology, 36, 304-310.

Stanton, M. E., Thomas, G. J., \& Brito, G. N. O. (1984). Posterodorsal septal lesions impair performance on both shift and stay working memory tasks. Behavioral Neuroscience, 98, 405-415.

Sutherland, R. J., \& DYck, R. H. (1984). Place navigation by rats in a swimming pool. Canadian Journal of Psychology, 38, 322-347.

Sutherland, R. J., Kolb, B. A., \& Whishaw, I. Q. (1982). Spatial mapping: Definitive disruption by hippocampal or medial frontal cortex damage in the rat. Neuroscience Letters, 31, 271-276.

Telang, S. D., \& EnNa, S. J. (1985). Ontogenetic development of central nervous system neurotransmitter receptors. In R. C. Wiggins, D. W. McCandless, \& S. J. Enna (Eds.), Developmental neurochemistry (pp. 225-247). Austin: University of Texas Press.

Thomas, G. J., \& BRITo, G. N. O. (1980). Recovery of delayed alternation in rats after lesions in medial frontal cortex and septum. Journal of Comparative \& Physiological Psychology, 94, 808-818.

VoGT, M. B., \& RuDY, J. W. (1984). Ontogenesis of learning: I. Variation in the rat's reflexive and learned responses to gustatory stimulation. Developmental Psychobiology, 17, 11-33.

Wagner, A. R., Rudy, J. W., \& WhitLow, J. W. (1973). Rehearsal in animal conditioning. Journal of Experimental Psychology, 97, 407-426.

Wikmark, R. G. E., Divak, I., \& Weiss, R. (1973). Delayed alternation in rats with lesions in the frontal lobes: Implications for a comparative neuropsychology of the prefrontal system. Brain, Behavior, \& Evolution, 8, 329-339.

Wirsching, B. A., Beninger, R. J., Jhamandas, K., Boggman, R. J., \& EL-Defrawy, S. R. (1984). Differential effects of scopolamine on working and reference memory in the radial arm maze. Pharmacology, Biochemistry \& Behavior, 20, 205-207.

(Manuscript received March 30, 1987; revision accepted for publication October $23,1987$. 